\title{
O SORO DO LEITE, SEUS PRINCIPAIS TRATAMENTOS E MEIOS DE VALORIZAÇÃO
}

\author{
Luane Alcântara Nunes* \\ Juliano Zaffalon Gerber** \\ Flávio Pietrobon Costa*** \\ Rafael José Santana Souza**** \\ Ricardo de Araújo Kalid ${ }^{* * * * *}$
}

RESUMO: Questões ambientais, associadas à produção de soro do leite pelas agroindústrias de laticínios, impulsionam buscas por alternativas que visem tanto a preservação do meio ambiente, quanto a agregação de valor a esse coproduto. Este artigo tem como objetivo discutir as vantagens, desvantagens, oportunidades e ameaças dos principais tratamentos e meios de valorização do soro do leite. Desta forma, a revisão de literatura apresenta como resultado uma discussão crítica sobre o contexto geral da empregabilidade atual do soro do leite e as implicações ambientais envolvidas.

PALAVRAS-CHAVE: Meio ambiente; Soro do leite; Alternativas.

\section{WHEY, ITS MAIN TREATMENTS AND MEANS OF VALORIZATION}

ABSTRACT: Environmental issues associated with the production of whey by dairies have triggered a search for alternatives which insist of the preservation of the environment and value aggregation to the co-product. Current paper discusses the advantages, disadvantages, opportunities and dangers of main treatments and valorization means of whey. Review of the literature forwards a critical discussion on the general context of the true use of whey and the involved environmental implications.

KEY WORDS: Environment; Whey; Alternatives.

\footnotetext{
Doutoranda do curso de Engenharia Industrial da Universidade Federal da Bahia (UFBA), Brasil. E-mail luane_alcantara@hotmail.com.

** Docente adjunto do Curso de Engenharia de Produção. Departamento de Ciências Exatas e Tecnológicas na Universidade Estadual de Santa Cruz (UESC), Brasil.

*** Docente do Mestrado em Desenvolvimento Regional e Meio Ambiente. Departamento de Ciências Exatas e Tecnológicas, Núcleo de Física Médica e Ambiental. Universidade Estadual de Santa Cruz (UESC), Brasil.

**** Graduando do curso de Engenharia de Produção da Universidade Estadual de Santa Cruz (UESC), Brasil.

${ }^{* * * * * *}$ Docente associado IV da Universidade Federal do Sul da Bahia (UFSB). Coordenador do Centro de formação de Ciências e Tecnologia. Brasil.
} 


\section{INTRODUÇÃO}

O soro do leite consiste em um coproduto lácteo das indústrias de laticínios que é extraído da coagulação do leite no processo fabril de queijos (BRASIL, 2013). Via de regra, para cada quilo de queijo, são necessários 10 litros de leite, sendo que deste processo produtivo saem 9 litros de soro de leite (MOREIRA et al., 2010). Com elevado valor nutricional, o coproduto soro do leite pode ser processado e se transformar em produtos com alto valor agregado (TEIXEIRA; FONSECA, 2008).

No entanto, estudos apontam que cerca de $40 \%$ do soro do leite produzido no Brasil é descartado de forma inadequada, principalmente pelas pequenas e médias empresas (MARQUARDT et al., 2012) transformando-se em um rejeito industrial nocivo à natureza e causando alto impacto ambiental, pelos prejuízos à fauna e flora, isso porque sua Decomposição Bioquímica de Oxigênio (DBO) é de dez a 100 vezes maior que a do esgoto doméstico (MOREIRA et al., 2010; PAULA et al., 2011).

Nos países desenvolvidos, tais como Estados Unidos e Irlanda, a proporção da utilização do soro do leite para a geração de novos produtos chega a $100 \%$ do volume produzido (BIEGER; LIMA, 2008). No entanto, no Brasil, convivese com a problemática de indicar caminhos para solucionar problemas ambientais relacionados ao seu descarte inadequado (FLORÊNCIO et al., 2013).

Nesse contexto, o presente artigo teve como objetivo identificar os principais tratamentos e meios de valorização do soro do leite, de forma a discutir sobre suas vantagens, desvantagens, oportunidades e ameaças.

\section{MATERIAL E MÉTODOS}

O estudo foi conduzido por meio de uma revisão sistemática da literatura. $\mathrm{O}$ primeiro passo foi estabelecer as palavras-chave da pesquisa. As palavras-chave foram direcionadas de acordo com as implicações ambientais do soro do leite, suas formas de tratamento e alternativas de valorização, tanto no idioma português quanto 
em inglês. As palavras-chave de busca, eleitas para contemplar as problemáticas abordadas neste estudo, foram soro do leite (Whey), queijo (cheese), resíduos (Waste), indústrias de laticínios (Dairy), impactos ambientais (Environmental Impacts), tratamentos (Treatments), valorização (Recovery), aproveitamento (Utilization or Use), nutrientes (Nutrients), cadeia produtiva (Supply Chain) e ciclo de vida (Life Cycle). Em seguida foram realizadas combinações de pares e trios das palavras-chave nos segmentos de busca das bases de dados.

A busca foi realizada nas bases Elsevier, Scielo, Web of Science e Google Scholar, com filtro para identificar periódicos, dissertações e teses de universidades estaduais e federais do Brasil. Também foram analisadas instruções normativas e legislações relacionadas. O horizonte de tempo das publicações também foi filtrado, parametrizado para identificar obras publicadas entre os anos de 2005 a 2016.

A seguir, demonstram-se os resultados da pesquisa quanto às (i) implicações ambientais do soro do leite, (ii) suas formas de tratamento e (iii) alternativas de valorização.

\section{IMPLICAÇÕES AMBIENTAIS DO SORO DO LEITE}

O início das discussões científicas acerca do soro do leite no meio ambiente já procede de um longo período. Illanes (2011) aborda em seu trabalho o aprimoramento do soro do leite e identifica a problemática ambiental segundo pesquisas de diversos autores, publicações que datam de meados da década de 70 .

As discussões ambientais do soro do leite evoluíram, no entanto, a essência continua intimamente relacionada com sua composição nutricional, que consiste de 93 a 94\% de água, 4, 4 a 5,0\% de lactose, 0,7 a 0,9\% de proteínas solúveis e 0,6 a 1,0\% de sais minerais (MANTOVANI et al., 2015), índices que variam de acordo com o seu tipo (soro doce ou soro ácido), o ingrediente usado para a coagulação, a forma de armazenamento e processamento do leite, além das condições do animal pelo qual o leite foi retirado (RAD; LEWIS, 2014).

$\mathrm{O}$ alto valor nutricional do soro do leite e seus benefícios entram em desacordo quando esse coproduto é desperdiçado e seu destino é o descarte efetuado 
de forma incorreta na natureza, pois, pela alta presença de matéria orgânica, causa prejuízos à fauna e flora das regiões. Quando o soro do leite é descartado no solo, compromete sua estrutura físico-química, diminuindo a qualidade e rendimento de eventuais colheitas (GONTHIER; 2013; ALVES, 2014; DEBOWSKI, 2014).

Quanto ao descarte do soro do leite na água, Gonthier (2013) comprovou a hipótese de que o soro do leite ácido tem efeito negativo sobre a vida microbiana e sua qualidade. $\mathrm{O}$ autor verificou que a turbidez da água aumentou exponencialmente com o aumento da quantidade de soro do leite, e a vida microbiana que ocorre naturalmente foi removida completamente com a presença de $150 \mathrm{~mL}$ de soro do leite para 946,35 $\mathrm{mL}$ de água.

Todos os trabalhos analisados citam o impacto nocivo do soro do leite no meio ambiente e as principais pesquisas estão voltadas para novas formas de tratamento (SARKAR et al. 2006), tipos de valorizações existentes (LIN et al., 2014), novas tecnologias (CARVALHO et al. 2013), elaboração de testes sensoriais em novos produtos (BOSI et al., 2013; MATOS, 2009), simulação de formas de utilização do soro (SILVA, 2011), além de estudo do ciclo de vida de algumas etapas do processo de fabricação, visando a colaboração para a produção e tecnologia mais limpa, com efeitos de redução dos impactos negativos (GONZÁLES-GARCIA et al., 2013; RAD; LEWIS, 2014; KIM et al., 2014).

\section{FORMAS DE TRATAMENTO DAS ÁGUAS RESIDUAIS COM SORO DO LEITE}

Com a grande pressão que as empresas vêm sofrendo em relação à melhoria de postura frente às questões ambientais, faz-se necessário que estas invistam em alternativas de tratamento dos seus resíduos e rejeitos (WISSMANN et al., 2013).

Para as agroindústrias de laticínios esse tratamento está relacionado às suas águas residuais, que são todas as águas descartadas provenientes do processo de fabricação dos produtos, da lavação de equipamentos e de outras atividades desenvolvidas, que não podem ser descartadas na rede pública de esgoto, nem em sistemas receptores sem o devido tratamento. No Brasil, regulam esses procedimentos a lei $\mathrm{n}^{\circ} 12305 / 10$ (BRASIL, 2010) e a resolução 430 de 2011 do Conselho Nacional do Meio Ambiente - Conama (BRASIL, 2011). 
Em uma revisão focada na investigação das principais formas de tratamento de efluentes de laticínios, Carvalho et al. (2013) identificaram três possibilidades: os processos biológicos, os tratamento físico-químico e os pantanais construídos. Podese afirmar que destes três processos de tratamentos do soro do leite derivam as demais pesquisas identificadas. A Figura 1 apresenta esquematicamente os procedimentos de tratamento derivados desses três processos, bem como a destinação dos produtos assim obtidos.

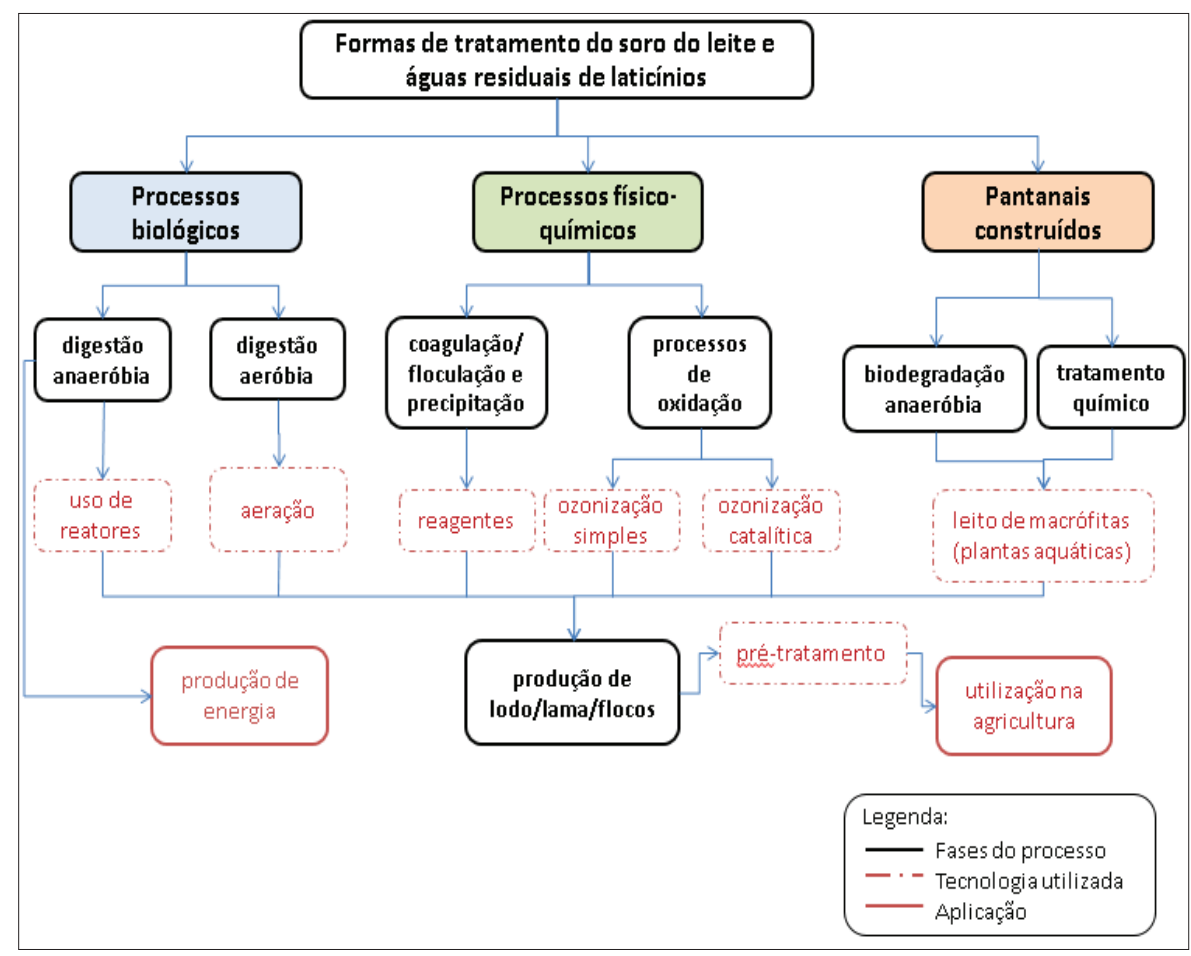

Figura 1. Processos de tratamento para o soro do leite e águas residuais de laticínios

Os processos biológicos podem ser realizados por meio da digestão anaeróbia e aeróbia. A diferença entre eles está no uso de micro-organismos que dependem ou não de oxigênio para a sua respiração. A digestão anaeróbia é comumente considerada como o único método viável de tratamento de águas residuais com elevada carga orgânica, e pode ser realizada com a utilização de reatores do tipo anaeróbio de manta de lodo (UASB) e de reatores de tanque continuamente agitado 
(CSTR) que têm a capacidade de recebimento de grande quantidade de carga orgânica e apresentam alta taxa de decomposição (CARVALHO et al., 2013).

A obtenção de energia está associada à utilização do processo anaeróbico por meio de reatores, porém não impede o uso de outras técnicas de tratamento e por vezes, o uso em conjunto de dois procedimentos melhora o desempenho do tratamento do resíduo e da produção de energia (DEBOWSKI et al., 2014; FLORÊNCIO et al. 2013; KELLY; HE, 2014).

Karadag et al. (2014) fornecem uma avaliação abrangente dos recentes relatórios sobre a produção fermentativa de hidrogênio por meio das águas residuais dos laticínios, trazendo parâmetros importantes e eficazes, que demonstram taxas volumétricas de produção de hidrogênio por litro de soro que variam de 0,23 a 2,9 $\mathrm{LH}_{2} \mathrm{~L}^{-1} \mathrm{~d}^{-1}$, pois depende do tipo do reator e do inóculo utilizado, além das condições do $\mathrm{pH}$ e temperatura.

A digestão aeróbica, por sua vez, é representada por sistemas de lodos ativados, possuidores de grandes quantidades de micro-organismos capazes de remover boa parte dos compostos (CARVALHO et al., 2013).

Os tratamentos físico-químicos podem ser obtidos por oxidação ou pela coagulação/floculação. A oxidação acontece por meio da aplicação de ozônio no resíduo, que pode reagir tanto com os compostos orgânicos (ozonização simples), quanto com a adição de metais, de forma a aumentar a eficiência do processo (ozonização catalítica) (ASSELIN et al., 2008).

Já a coagulação/floculação se apresenta como um sistema de maior simplicidade e economia. A coagulação consiste no processo de aplicação de reagentes que desestabilizam as partículas coloidais em suspensão, e essas posteriormente se unem formando partículas maiores denominadas de flocos que serão removidos em seguida (GUGLIELMOTTI et al., 2011).

O tratamento por pantanais construídos, também denominados de Sistemas Alagados Construídos (SAC) ou Sistemas Wetlands, consiste em uma área controlada receptora de águas residuais, que envolve um mecanismo de filtração, de degradação microbiana da matéria orgânica por biofilmes aderidos e de absorção de nutrientes e poluentes pelas vegetações de macrófitas aquáticas presentes (MENDONÇA et al., 2015; MATOS et al., 2010). 
Mendonça et al. (2015) afirmam que esses sistemas vêm ganhando popularidade e está sendo utilizado por grande número de laticínios no exterior, pela eficácia na remoção de DBO das águas residuais e do baixo custo de implantação e monitoramento em comparação aos demais sistemas convencionais.

No Quadro 1 estão expostos os principais tratamentos em ordem de maior utilização, as vantagens e desvantagens associadas ao seu uso.

Quadro 1. Os principais tratamentos de águas residuais de laticínios, suas vantagens e desvantagens

\begin{tabular}{|c|c|c|c|}
\hline Tratamentos & Vantagens & Desvantagens & Referências \\
\hline \multirow{3}{*}{ Anaeróbico } & $\begin{array}{l}\text { - Alta decomposição do } \\
\text { resíduo; }\end{array}$ & • Produção de lodo/lama; & \multirow{3}{*}{$\begin{array}{l}\text { CARVALHO et al. } \\
\text { 2013; FRIGON, et } \\
\text { al., 2009; KELLY; HE, } \\
\text { 2014; KARADAG et al. } \\
\text { 2014. }\end{array}$} \\
\hline & $\begin{array}{l}\text { - Capacidade de } \\
\text { recebimento de alta } \\
\text { carga orgânica; }\end{array}$ & \multirow[t]{2}{*}{$\begin{array}{l}\text { Exige manutenção e } \\
\text { custos de limpeza. }\end{array}$} & \\
\hline & $\begin{array}{l}\text { - Pode produzir energia } \\
\text { com auxílio de outras } \\
\text { técnicas. }\end{array}$ & & \\
\hline \multirow{3}{*}{ Aeróbico } & \multirow{3}{*}{$\begin{array}{l}\text { - Capaz em remover } \\
\text { compostos orgânicos } \\
\text { das águas. }\end{array}$} & • Produção de lodo/lama; & \multirow{3}{*}{$\begin{array}{l}\text { CARVALHO et al. } \\
\text { 2013; FRIGON, et } \\
\text { al., 2009; RIVAS et al. } \\
2010 .\end{array}$} \\
\hline & & $\begin{array}{l}\text { Exige manutenção e } \\
\text { custos de limpeza; }\end{array}$ & \\
\hline & & - Custos com energia. & \\
\hline \multirow{3}{*}{$\begin{array}{l}\text { Físico- } \\
\text { químicos }\end{array}$} & - Pré-tratamento; & \multirow{3}{*}{$\begin{array}{l}\text { - Não é suficiente para } \\
\text { utilização isolada no } \\
\text { tratamento das águas } \\
\text { residuais. }\end{array}$} & \multirow{3}{*}{$\begin{array}{l}\text { ASSELIN et al., 2008; } \\
\text { GUGLIELMOTTI et } \\
\text { al., 2011; LOLOEI et } \\
\text { al., 2014; RIVAS et al., } \\
2011 .\end{array}$} \\
\hline & $\begin{array}{l}\text { - Eficiente para a redução } \\
\text { da DBO; }\end{array}$ & & \\
\hline & $\begin{array}{l}\text { - Utilização dos flocos } \\
\text { como biofertilizante na } \\
\text { agricultura. }\end{array}$ & & \\
\hline $\begin{array}{l}\text { Pantanais } \\
\text { construídos }\end{array}$ & $\begin{array}{l}\text { - Eficiente para a redução } \\
\text { da DBO; } \\
\text { - Baixo custo de } \\
\text { implantação. }\end{array}$ & $\begin{array}{l}\text { - Pequenas vazões de } \\
\text { resíduos; } \\
\text { - Exige análises laboratoriais } \\
\text { constantes. }\end{array}$ & $\begin{array}{l}\text { CARVALHO et } \\
\text { al., 2013; MATOS } \\
\text { A. et al., 2010; } \\
\text { MENDONÇA et al., } \\
2015 .\end{array}$ \\
\hline
\end{tabular}


O Quadro 2, por sua vez, mostra a estimativa dos principais custos para aplicação desses sistemas.

Quadro 2. Estimativa de custos das principais formas de tratamento

\begin{tabular}{|c|c|c|c|}
\hline Formas de tratamento & $\begin{array}{l}\text { Custo principal de } \\
\text { aplicação/ } \mathrm{m}^{3}\end{array}$ & $\begin{array}{l}\text { Área/Volume } \\
\text { tratado }\end{array}$ & Referência \\
\hline $\begin{array}{l}\text { Processos biológicos } \\
\text { aeróbicos }\end{array}$ & $\mathrm{R} \$ 125.000,00$ & $450 \mathrm{~m}^{2} / 900 \mathrm{~m}^{3}$ & (BARANA et al., 2012) \\
\hline $\begin{array}{l}\text { Processos biológicos } \\
\text { anaeróbicos }\end{array}$ & $\mathrm{R} \$ 1.888,90$ & $\begin{array}{c}6,80 \mathrm{~m}^{2} / 32,65 \\
\mathrm{~m}^{3}\end{array}$ & $\begin{array}{l}\text { (ALMEIDA; GROSSI, } \\
\text { 2014) }\end{array}$ \\
\hline $\begin{array}{l}\text { Processos químicos } \\
\text { físicos }\end{array}$ & $\begin{array}{c}\$ 30,00-60,00 / \mathrm{kg} \text { de } \\
\text { coagulante }\end{array}$ &.$-* / 1000 \mathrm{~m}^{3}$ & (PAVANELI, 2001) \\
\hline Pantanais construídos & $\mathrm{R} \$ 1.000,00-1.500,00$ & $\begin{array}{c}3,00 \mathrm{~m}^{2} / 200 \\
\mathrm{~m}^{3 * *}\end{array}$ & (MONTEIRO, 2009) \\
\hline
\end{tabular}

*sem dados; **por minuto

\section{PRINCIPAIS FORMAS DE VALORIZAÇÃO DO SORO DO LEITE}

Basicamente, o soro do leite pode ser valorizado quando é utilizado como matéria-prima de novos produtos, sendo que o seu aproveitamento está associado à alimentação humana, à alimentação animal, à geração de energia e ao reúso na agricultura. Na Figura 2 é exposta uma visão geral das fases do soro do leite, em relação ao seu estado físico e componentes extraídos, fazendo uma associação com as tecnologias envolvidas no processo e as aplicações mais usuais. 


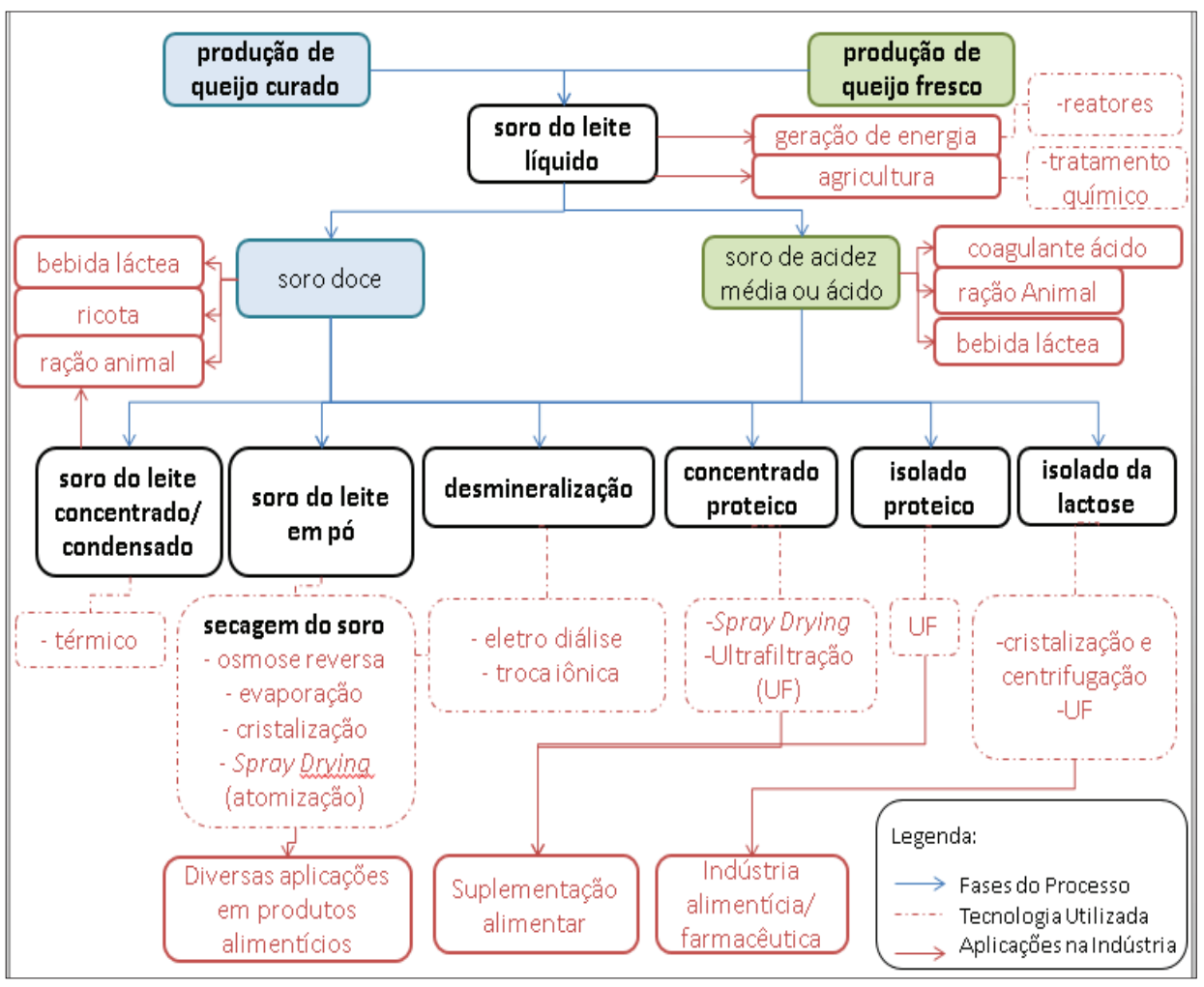

Figura 2. O soro do leite, suas fases, tecnologias e aplicações na indústria

Tanto o soro doce quanto o soro ácido podem ser utilizados como substrato na geração de energia ou biocombustíveis e receber um pré-tratamento químico para reutilização na agricultura (LIN et al., 2014; TONI et al., 2012).

O soro doce é o que possui maior aplicabilidade industrial; pode ser aproveitado, ainda na forma líquida direta ou com a realização da condensação para a produção de queijos frescos (ricota ou cottage), bebidas lácteas e fornecimento direto para alimentação animal. Quando na forma em pó, as aplicabilidades do soro do leite aumentam significativamente, pois pode ser adicionado em diversos produtos alimentares como um substituto parcial ou total do leite em pó. As vantagens da substituição estão relacionadas ao baixo teor de gordura e lactose e ao aumento das propriedades nutricionais em relação às proteínas, vitaminas e sais minerais. As desvantagens encontradas nesta forma de aplicação são os altos custos 
dos equipamentos para transformação do soro líquido em pó (MIRABELLA et al., 2014).

Os custos, para serem compensados, necessitam de grande demanda, bom planejamento da produção e estratégias de mercado (NUNES, 2016).

Quanto às aplicações industriais do soro ácido nos alimentos, seja na forma líquida direta, condensada ou em pó, pode-se afirmar que estas apresentam limitações. Isso ocorre porque o soro do leite ácido confere sabor salinizado ou ácido aos alimentos, logo, estudos estão sendo desenvolvidos, visando melhorar a aplicabilidade do soro ácido em produtos para que estes passem a ter boa aceitabilidade sensorial (OLIVEIRA, 2011).

No Quadro 3 é demonstrada uma estimativa dos custos operacionais e do valor de mercado das principais formas de aproveitamento do soro do leite.

Quadro 3. Custos operacionais e valor de mercado das principais formas de aproveitamento do soro do leite

\begin{tabular}{|c|c|c|c|}
\hline Produto & Custos operacionais & Valor de mercado & Referência \\
\hline Ricota & $\mathrm{R} \$(0,90$ a 3,79$) / \mathrm{kg}$ & $\mathrm{R} \$ 12,00 / \mathrm{kg}$ & $\begin{array}{l}\text { PORTO et al., 2005; } \\
\text { CARLI et al. } 2012 .\end{array}$ \\
\hline Bebida láctea & $\mathrm{R} \$ 0,75 / \mathrm{L}$ & $\mathrm{R} \$ 1,40 / \mathrm{L}$ & $\begin{array}{l}\text { MADERI et al., } \\
2014 .\end{array}$ \\
\hline Soro em pó & ${ }_{-}^{*}$ & $\mathrm{R} \$(4,50$ a 10,00$) / \mathrm{kg}$ & MFRURAL, 2015. \\
\hline $\begin{array}{l}\text { Lactose } \\
(34 \% \text { a } 80 \%)\end{array}$ & $\mathrm{R} \$(0,86$ a 0,98$) / \mathrm{Kg}$ & $\mathrm{R} \$ 4,80 / \mathrm{kg}$ & SILVA, 2011. \\
\hline $\begin{array}{l}\text { Concentrado proteico } \\
\text { do soro } \\
(35 \% \text { a } 80 \%)\end{array}$ & $\mathrm{R} \$(4,29$ a 12,46$) / \mathrm{Kg}$ & $\mathrm{R} \$(7,40$ a 23,70$) / \mathrm{kg}$ & SILVA, 2011. \\
\hline Etanol (34 \% a $80 \%)$ & $\mathrm{R} \$(2,79$ a 2,95$) / \mathrm{L}$ & $\mathrm{R} \$ 1,05 / \mathrm{L}$ & SILVA, 2011. \\
\hline Ração animal & $\mathrm{R} \$ 0,01 / \mathrm{L}$ & $\mathrm{R} \$ 0,00 / \mathrm{L}$ & COSTA et al., 2010. \\
\hline
\end{tabular}

*sem dados

Sendo assim, utilizando como critério de seleção o custo benefício das principais formas de aproveitamento do soro do leite, apresenta-se a seguir detalhes das discussões sobre os produtos: bebida láctea, ricota e derivados das tecnologias 
de secagem e ultrafiltração, além das discussões sobre a alternativa de destinar o soro para alimentação animal.

\subsection{BEBIDA LÁCTEA}

A produção de bebidas lácteas no Brasil torna-se uma interessante alternativa de aproveitamento do soro de leite (BOSI et al., 2013), pelas características predominantes de pequenas e médias empresas, que não se interessam em efetuar grandes investimentos para processar o soro para a forma em pó, forma que geralmente garante maiores rendimentos e aplicabilidades em larga escala (MADERI, 2014; SILVA, 2011).

Pesquisas estão sendo elaboradas visando à obtenção de uma fórmula adequada de bebida láctea não fermentada, com o objetivo de aumentar suas propriedades nutricionais, sua palatabilidade e o consequente interesse do consumidor (PELEGRINE; CARRASQUEIRA, 2008; KOFFI et al., 2005; VENTURINI FILHO, 2010).

A compilação bibliográfica dos resultados das características físico-químicas das bebidas lácteas formuladas com diferentes proporções, com o uso tanto de soro do leite doce quanto de soro de leite ácido, além de outros componentes, é apresentada no Quadro 4.

Quadro 4. Resultados das características físico-químicas das bebidas lácteas formuladas com diferentes proporções de soro do leite.

(Continua)

\begin{tabular}{|c|c|c|l|c|c|c|c|c|c|c|}
\hline $\begin{array}{c}\text { Tipo de } \\
\text { soro }\end{array}$ & $\begin{array}{c}\text { Soro } \\
(/ \%)\end{array}$ & $\begin{array}{c}\text { Pré- } \\
\text { tratamento }\end{array}$ & $\begin{array}{l}\text { Outros } \\
\text { ingredientes }\end{array}$ & $\mathrm{pH}$ & $\begin{array}{c}\text { Ac. } \\
\text { látic. } \\
(/ \%)\end{array}$ & $\begin{array}{c}\text { Gord. } \\
(/ \%)\end{array}$ & $\begin{array}{c}\text { Prot. } \\
(/ \%)\end{array}$ & $\begin{array}{c}\text { Visc. } \\
(/ \mathrm{cP})\end{array}$ & $\begin{array}{c}\text { Aceitação } \\
(/ \%)\end{array}$ & Referência \\
\hline $\begin{array}{c}\text { Queijo } \\
\text { frescal }\end{array}$ & 20 & Térmico & $\begin{array}{l}10 \% \text { leite de } \\
\text { búfala, } 70 \% \\
\text { iogurte de búfala }\end{array}$ & 5,04 & 0,32 & 8,7 & 3,22 & 2913 & 80,02 & $\begin{array}{c}\text { (CALDEIRA } \\
\text { et al., 2010) }\end{array}$ \\
\hline
\end{tabular}


(Conclusão)

\begin{tabular}{|c|c|c|c|c|c|c|c|c|c|c|}
\hline $\begin{array}{c}\text { Tipo de } \\
\text { soro }\end{array}$ & $\begin{array}{c}\text { Soro } \\
(/ \%)\end{array}$ & $\begin{array}{c}\text { Pré- } \\
\text { tratamento }\end{array}$ & $\begin{array}{l}\text { Outros } \\
\text { ingredientes }\end{array}$ & $\mathrm{pH}$ & $\begin{array}{l}\text { Ac. } \\
\text { látic. } \\
\text { (/\%) }\end{array}$ & $\begin{array}{c}\text { Gord. } \\
(/ \%)\end{array}$ & $\begin{array}{l}\text { Prot. } \\
(/ \%)\end{array}$ & $\begin{array}{l}\text { Visc. } \\
(/ \mathrm{cP})\end{array}$ & $\begin{array}{c}\text { Aceitação } \\
(/ \%)\end{array}$ & Referência \\
\hline $\begin{array}{l}\text { Queijo } \\
\text { Minas } \\
\text { frescal }\end{array}$ & 60 & Não & $\begin{array}{l}25 \% \text { polpa de } \\
\text { acerola, 10\% } \\
\text { açúcar, 39\% } \\
\text { água, } 0,75 \% \text { fibra } \\
\text { solúvel (Inulina) }\end{array}$ & 6,59 & 0,1 & - $^{*}$ & ${ }^{*}$ & - $^{*}$ & 80,4 & $\begin{array}{c}\text { (BOSI et al., } \\
\text { 2013) }\end{array}$ \\
\hline $\begin{array}{c}\text { Queijo } \\
\text { muçarela }\end{array}$ & 70 & Térmico & $\begin{array}{l}20 \% \text { leite, } 9 \% \\
\text { açúcar, } 1 \% \text { cacau, } \\
0,2 \% \text { estabilizante, } \\
0,05 \% \text { citrato } \\
\text { de sódio, } 0,07 \% \\
\text { aroma }\end{array}$ & ${ }^{*}$ & ${ }^{*}$ & - $^{*}$ & ${ }^{*}$ & - $^{*}$ & 99 & $\begin{array}{c}\text { (MARCHI et } \\
\text { al., 2012) }\end{array}$ \\
\hline $\begin{array}{c}\text { Queijo } \\
\text { muçarela }\end{array}$ & 20 & Térmico & $\begin{array}{l}70 \% \text { leite } \\
\text { fermentado, 10\% } \\
\text { de açúcar, 30\% } \\
\text { de infusão de } \\
\text { Camellia sinensis }\end{array}$ & 4,6 & 0,61 & 1,1 & 3,6 & 946 & 70 & $\begin{array}{c}\text { (RIBEIRO, } \\
\text { 2013) }\end{array}$ \\
\hline $\begin{array}{c}\text { Queijo } \\
\text { muçarela }\end{array}$ & 55 & Não & $\begin{array}{l}4 \% \text { de leite em } \\
\text { pó, } 0,1 \% \text { de } \\
\text { fosfato, } 25 \% \text { de } \\
\text { polpa, } 12 \% \text { de } \\
\text { açúcar }\end{array}$ & 3.93 & 0.8 & 1,8 & 3 & 2061 & 62,32 & $\begin{array}{c}\text { (MATOS, } \\
\text { 2009) }\end{array}$ \\
\hline $\begin{array}{c}\text { Queijo } \\
\text { muçarela }\end{array}$ & 40 & $\begin{array}{c}\text { Remoção de } \\
\text { gorduras, } \\
\text { Filtrado e } \\
\text { pasteurizado }\end{array}$ & $\begin{array}{l}34 \% \text { de leite } \\
\text { integral, 1,25\% } \\
\text { leite em pó } \\
\text { desnatado, } 12 \% \\
\text { polpa de manga, } \\
12 \% \text { de açúcar }\end{array}$ & 3,83 & 0,98 & 0,83 & - & - $^{*}$ & 82 & $\begin{array}{c}\text { (SANTOS et } \\
\text { al., 2008) }\end{array}$ \\
\hline $\begin{array}{l}\text { Queijo } \\
\text { lanche }\end{array}$ & 33,3 & $\begin{array}{c}\text { Térmico, } \\
\text { filtrado }\end{array}$ & $\begin{array}{l}30 \% \text { de extrato } \\
\text { hidrossolúvel de } \\
\text { soja, } 36,6 \% \text { de } \\
\text { leite, } 15 \% \text { açúcar, } \\
15 \% \text { polpa de } \\
\text { pêssego, } 0,1 \% \\
\text { aroma e } 0,1 \% \\
\text { corante }\end{array}$ & 4,93 & 0,9 & - $^{*}$ & - & - $^{*}$ & 76,4 & $\begin{array}{c}\text { (KEMPKA et } \\
\text { al., 2008) }\end{array}$ \\
\hline
\end{tabular}

Ac. látic. - Ácido lático; Gord. - Gordura; Prot.- Proteína; Visc. - Viscosidade; *sem dados 


\subsection{RICOTA}

O aproveitamento do soro do leite para a fabricação de ricota é considerado como boa oportunidade de crescimento do negócio e encontra-se como alternativa viável para evitar o descarte inadequado do mesmo. Essa afirmativa se justifica, principalmente, pois, quando a produção é em baixa escala, praticamente se utilizam os mesmos equipamentos que foram necessários para a fabricação dos queijos comuns (DETONI; GONÇALVES, 2011).

Referente aos custos decorrentes do processo produtivo, estes não são considerados elevados, nem de difícil administração (CARLI et al., 2012). As desvantagens associadas à fabricação de ricota estão relacionadas a este produto ainda por gerar resíduo, o soro da ricota, que se torna descartável e de difícil aproveitamento pelo grau de acidez e baixos nutrientes disponíveis (BITELLO et al., 2013).

\subsection{PRODUTOS ORIUNDOS DAS TECNOLOGIAS DE SECAGEM E ULTRAFILTRAÇÃO}

Tanto o soro do leite doce quanto o ácido podem ser secos pela tecnologia de Spray Drying (secagem por aspersão), e/ou ainda passar por outros tratamentos, visando à retirada dos componentes nutricionais mais importantes através da Ultrafiltração (UF). As etapas e layouts para processamento do soro do leite podem variar do mais simples aos mais aprimorados (LIRA et al., 2009).

A tecnologia de secagem por aspersão consiste na retirada da água dos elementos para a obtenção de pós e grânulos (OLIVEIRA; PETROVICK, 2010). A Ultrafiltração - UF, entretanto, é uma tecnologia caracterizada por um processo onde o líquido passa por membranas de filtração preenchidas por microporos que permitem a separação das moléculas de interesse (LIRA et al., 2009).

O soro do leite quando em pó possui diversas aplicabilidades na indústria alimentícia, sendo utilizado como um produto de alto valor nutricional que pode ser empregado na confecção de produtos cárneos (YETIM et al., 2006), panificação (VALDUGA et al., 2006; LIMA et al., 2009), biscoitos, sorvetes (SILVA; BOLINI, 
2006), bebidas, chocolates, fármacos, rações e suplementação alimentar esportiva e nutricional (FISCHBORN, 2009; OLIVEIRA et al., 2012; OLIVEIRA et al., 2008; SOUZA; JERÔNIMO, 2012).

O Brasil foi grande importador de soro do leite em pó nas últimas décadas atingindo a importação de cerca de 40 mil toneladas do produto em 2008, porém este cenário vem mudando nos últimos anos a partir dos investimentos industriais nas tecnologias de processamento deste insumo, e o país vem substituindo as importações e aumentando a sua produção doméstica (RIBEIRO; LACERDA, 2012).

Silva (2011) avaliou os riscos, o impacto poluidor e as viabilidades técnica e econômica de uma unidade de processamento do soro para produção de Concentrado Proteico do Soro de Leite - CPS em diferentes concentrações de proteína, chegando à conclusão que a produção do maior concentrado se apresentou mais viável em contrapartida com a menor redução do impacto poluidor. Foram feitos, também, a construção de diferentes cenários, analisando em paralelo, a produção de lactose em pó, etanol hidratado e etanol combustível hidratado.

$\mathrm{O}$ autor verificou que apenas a produção de lactose em pó em associação com o CPS se mostrou técnica e economicamente viável e colaborou para a redução da carga poluidora do soro, porém todas essas observações foram consideradas válidas para uma quantidade disponível de soro acima de $700 \mathrm{~m}^{3}$ por dia. Nunes (2016) também corrobora com essa afirmação enfatizando em sua pesquisa que são necessários cerca de $2.000 \mathrm{~L}$ de soro para se obter $1 \mathrm{~kg}$ de CPS.

\subsection{ALIMENTAÇÃO ANIMAL}

A utilização do soro do leite como um aditivo alternativo na alimentação dos animais, quando doado pelos produtores de queijo, colabora com a diminuição dos custos dos criadores de animais e, portanto, da dependência de grãos. Consiste também em uma alternativa auxiliar para a destinação do soro, porém, essa opção é válida apenas quando bem administrada e quando ofertada na dose correta para o animal (MARTINS et al., 2008).

Alguns estudos vêm sendo efetuados para analisar a diferença da conversão alimentar e o desenvolvimento dos animais que recebem dietas com soro do leite. 
A inserção de até 5\% de soro de leite em pó, como fonte alternativa de lactose, foi indicada para a alimentação de aves (Gamba et al., 2006).

Hauptli (2005) verificou que a utilização de soro de leite integral deve ser realizada em níveis de até $21 \%$ nas dietas para leitões. Costa et al. (2010) verificaram que o aleitamento de cabritos com até $45 \%$ de soro do leite é o máximo recomendado. Martins et al. (2008) constataram que o soro de queijo líquido pode ser administrado para suínos em crescimento em substituição pelos grãos em até $30 \%$. Além disso, Maderi (2014) destaca que quando o soro é ofertado aos suínos, sem controle de quantidade, são identificadas algumas mortes, ocasionadas pelo aumento dos gases intestinais.

De modo a possibilitar a demonstração do contexto geral de empregabilidade atual do soro do leite, no Quadro 5 são mostradas as vantagens e desvantagens das principais possibilidades de valorização e aproveitamento do soro do leite.

Quadro 5. Vantagens e desvantagens das principais possibilidades de valorização e aproveitamento do soro do leite

(Continua)

\begin{tabular}{|c|c|c|c|}
\hline Alternativa & Vantagens & Desvantagens & Referências \\
\hline Bebida láctea & $\begin{array}{l}\text { - Produto saudável; } \\
\text { - Alta aceitabilidade; } \\
\text { - Elevado valor } \\
\text { nutricional; Permite a } \\
\text { variação de sabores; } \\
\text { - Baixo investimento; } \\
\text { - Alto aproveitamento de } \\
\text { soro do leite. }\end{array}$ & $\begin{array}{l}\text { - Necessidade de } \\
\text { espessantes. }\end{array}$ & $\begin{array}{l}\text { BOSI et al., 2013; } \\
\text { CALDEIRA et al., 2010; } \\
\text { CRUZ, 2006; MARCHI } \\
\text { et al., 2012; RIBEIRO, } \\
\text { 2013; CAPITANI et al., } \\
\text { 2005; MADERI, 2014; } \\
\text { SILVA, 2011; MATOS, } \\
\text { 2009; FONTAN, 2008. }\end{array}$ \\
\hline Ricota & $\begin{array}{l}\text { - Produto saudável; } \\
\text { - Baixo teor de gordura; } \\
\text { - Fácil digestão; } \\
\text { - Garante aumento das } \\
\text { receitas; } \\
\text { - Baixos custos; } \\
\text { - Mesmo mercado } \\
\text { consumidor. }\end{array}$ & $\begin{array}{l}\text { - Alta perecibilidade; } \\
\text { - Ainda produz resíduo; } \\
\text { - Resíduo não aproveitado e } \\
\text { geralmente descartado. }\end{array}$ & $\begin{array}{l}\text { DETONI \& } \\
\text { GONÇALVES, 2011; } \\
\text { BEZERRA, 2008 } \\
\text { CARLI et al., 2012; } \\
\text { SILVA \& FERREIRA, } \\
2010 ; \text { PORTO et al., } \\
2005 \text {; BITELLO et al. } \\
2013 \text {. }\end{array}$ \\
\hline
\end{tabular}


(Conclusão)

\begin{tabular}{|c|c|c|c|}
\hline Alternativa & Vantagens & Desvantagens & Referências \\
\hline $\begin{array}{c}\text { Produtos - } \\
\text { tecnologias } \\
\text { de secagem e } \\
\text { ultrafiltração }\end{array}$ & $\begin{array}{l}\text { - Valorização de um } \\
\text { resíduo ou coproduto; } \\
\text { - Crescimento do negócio; } \\
\text { - Elevado ganho } \\
\text { econômico; } \\
\text { - Amplo mercado } \\
\text { consumidor. }\end{array}$ & $\begin{array}{l}\text { - Viável para quantidades } \\
\text { acima de } 700 \mathrm{~m}^{3} \text { de soro } \\
\text { do leite; } \\
\text { - Qualidade do soro; } \\
\text { - Custos altos dos } \\
\text { equipamentos; } \\
\text { - Custos logísticos altos; } \\
\text { - Limitação para pequenas e } \\
\text { médias queijarias. }\end{array}$ & $\begin{array}{l}\text { BEECHER et al., 2008; } \\
\text { GUIMARÃES et al., } \\
2010 ; \quad \text { FISCHBORN, } \\
2009 . \\
\text { OLIVEIRA C., et } \\
\text { al., 2008; SILVA, } \\
\text { 2011; JELEN, 2009. } \\
\text { BALDISSERA et al., } \\
\text { 2011; HARAGUCHI } \\
\text { et al., 2006; NUNES, } \\
2016 ;\end{array}$ \\
\hline $\begin{array}{c}\text { Alimentação } \\
\text { animal }\end{array}$ & $\begin{array}{l}\text { - Baixo custo para o } \\
\text { criador de animais; } \\
\text { - Menor utilização de } \\
\text { ração ou grãos; } \\
\text { - Alternativa alimentar } \\
\text { para os animais. }\end{array}$ & $\begin{array}{l}\text { - Proporção limitada para } \\
\text { cada animal; } \\
\text { - Exige uma administração } \\
\text { logística para } \\
\text { caracterizar-se como } \\
\text { uma boa alternativa de } \\
\text { aproveitamento do soro; } \\
\text { - Associação com o descarte } \\
\text { inadequado no meio } \\
\text { ambiente. }\end{array}$ & $\begin{array}{l}\text { MARTINS et al., 2008; } \\
\text { COSTA et al., 2010; } \\
\text { HAUPTLI, 2005; } \\
\text { GAMBÁ et al., 2006; } \\
\text { MADERI, 2014; } \\
\text { CETESB, 2008. } \\
\text { MIZUBUTI, 1994. }\end{array}$ \\
\hline
\end{tabular}

\section{CONSIDERAÇÕES FINAIS}

Foi possível identificar que as implicações ambientais relacionadas ao soro do leite só devem ser consideradas quando as empresas empregam o descarte inadequado do soro no meio ambiente, ou na rede de esgoto, ou ainda quando não realizam um tratamento eficiente do efluente, sem considerar os impactos relacionados ao ciclo de vida de um novo produto.

Em relação às formas de tratamento e formas de valorização foi possível observar, respectivamente, que os processos biológicos anaeróbicos e os pantanais construídos demonstram maiores vantagens no tratamento das águas residuais com soro e que a bebida láctea apresenta-se como a melhor alternativa de aproveitamento 
do soro para pequenas e médias empresas.

Em contrapartida, observou-se que a destinação do soro à alimentação animal não é uma alternativa adequada de valorização ou aproveitamento, pois exige uma administração logística eficaz e de difícil controle.

Com a realização deste trabalho pode-se concluir que para um beneficiamento em escala industrial do soro são necessários estudos que visem determinar a viabilidade do empreendimento quanto à quantidade e qualidade disponível do soro e com relação à capacidade de consumo do mercado.

\section{AGRADECIMENTOS}

Os autores são gratos à Coordenadoria de - Capes, pelo apoio à pesquisa.

\section{REFERÊNCIAS}

ALVES, M. P.; MOREIRA, R. O.; JÚNIOR, P.; MARTINS, M. C. F.; PERRONE, I.; CARVALHO, A. Soro de leite: tecnologias para o processamento de coprodutos. Rev. Inst. Laticínios Cândido Tostes, v. 69, n. 3, p. 212-226, 2014.

ASSELIN, M.; DROGUI, P.; BENMOUSSA, H.; BLAIS, J. Effectiveness of electrocoagulation process in removing organic compounds from slaughterhouse wastewater using monopolar and bipolar electrolytic cells. Chemosphere, v. 72, n. 11, p. 1727-1733, 2008.

BALDISSERA, A. C.; BETTA, F. D.; PENNA, A. L. B.; LINDNER, J. D. D. Alimentos funcionais: uma nova fronteira para o desenvolvimento de bebidas proteicas a base de soro de leite. Semina: Ciências Agrárias, v. 32, n. 4, p. 1497-1512, 2011.

BARANAA.; LIMA R.; BOTELHO V.; SIMÕES D. Desenvolvimento de uma bebida láctea fermentada feita com soro ácido de queijo quark. Revista Verde de Agroecologia e Desenvolvimento Sustentável, v. 7, n. 5, p. 13-21, 2012.

BEECHER, J.; DRAKE, M.; LUCK, P.; FOEGEDING, E. Factors regulation astringency of whey protein beverages. Journal of Dairy Science, Madison, v. 91, n. 7, p. 2553- 
2560, 2008.

BEZERRA, J. Tecnologia da fabricação de derivados do leite. Departamento de Engenharia de Alimentos: Boletim Técnico. Ed. Unicentro, 2008. 56 p.

BIEGER, A.; LIMA, J. Empresa e desenvolvimento sustentável: um estudo de caso da Sooro. Revista FAE Curitiba, v.11, n.2, p.59-67, 2008.

BITELLO, A.; VINCENZI,A.; FACCIN, C.; GRÄFF, C.; SCHLABITZ, C.; BURLANIBITELLO, A. Aproveitamento do soro de ricota para produção de diferentes biomoléculas utilizando a luyveromyces marxianus. Revista Destaques Acadêmicos, v. 5, n. 4, 2013.

BOSI, M. G.; BERNABÉ, B. M.; LUCIA, S.M.D.; E ROBERTO, C. D. Bebida com adição de soro de leite e fibra alimentar prebiótica. Pesquisa Agropecuária Brasileira, v.48, n.3, p.339-341, 2013.

BRASIL. Conselho Nacional de Meio Ambiente - CONAMA. Resolução n ${ }^{0}$ 430, de 13 de maio de 2011. Dispõe sobre condições e padrões de lançamento de efluentes, complementa e altera a Resolução n ${ }^{\circ} 357$, de 17 de março de 2005, do Conselho Nacional do Meio Ambiente - CONAMA. Diário Oficial da União. 2011.

BRASIL. Ministério da Agricultura, Pecuária e Abastecimento (MAPA). Estabelece os padrões de identidade e qualidade de soro de leite. Instrução Normativa $\mathrm{n}^{0} \mathbf{5 3}$, 25 de agosto de 2013.

BRASIL. Ministério do meio ambiente. Lei $\mathrm{n}^{\mathrm{0}} 12305$ que institui a Política Nacional de Resíduos Sólidos. Diário oficial da União. Brasília, 02 de agosto de 2010.

CALDEIRA, L. A.; FERNANDES, S. A. A.; MAGNAVITA, A. P. A.; FERRÃO, S. P. B.; SANTOS, T. D. R. Ciência Rural Santa Maria, v.40, n.10, p.2193-2198, 2010.

CAPITANI, C.; PACHECO, M.; GUMERATO, H.; VITALI, A.; SCHMIDT, F. Recuperação de proteínas do soro de leite por meio de coacervação com polissacarídeo. Pesquisa Agropecuária Brasileira. v.40, n.11, p.1123-1128, 2005. 
CARLI, B. S.; MARCELLO, I. E.; GOMES, G.; HEIN, N. Métodos de atribuição de custos conjuntos aplicados ao setor de laticínio: estudo de caso no laticínio Boa Esperança do Iguaçu Ltda. Custos e @gronegócio online, v. 8, n. 1, 2012

CARVALHO, F.; PRAZERES, A. R.; RIVAS, J. Cheese whey wastewater: Characterization and treatment. Science of the Total Environment, v. 445-446, 2013.

CETESB. Companhia de Tecnologia de Saneamento Ambiental. Guia Técnico ambiental da Indústria de Produtos Lácteos. [s.l.; s.n.]: 2008. 95p. (Série P+L. SENAI)

COSTA, R.; FILHO, E.; MEDEIROS, G.; VILLARROEL, A.; CRUZ, S.; SANTOS, E. Substituição do leite de cabra por soro de queijo bovino para cabritos alpinos. Rev. Bras. Zootec, v. 39, n. 4, p. 824-830, 2010.

CRUZ, A.G. Milk Drink Using Whey Butter Cheese. Ciência e Tecnologia de Alimentos, v. 26, p. 116-122, 2006.

D BOWSKI, M.; KORZENIEWSKA, E.; FILIPKOWSKA, Z.; ZIELI SKI, M.; KWIATKOWSKI, R. Possibility of hydrogen production during cheese whey fermentation process by different strains of psychrophilic bacteria. Int J Hydrogen Energy, v. 39, p.19721978, 2014.

DETONI, E.; GONÇALVES, L. A. Desenvolvimento de creme de ricota condimentado com tomate seco e manjericão. 2011. 45f. Dissertação (Graduação em Tecnologia em Alimentos) Universidade Tecnológica Federal do Paraná, Francisco Beltrão, 2011.

FISCHBORN, S. A influência do tempo de ingestão da suplementação de whey protein em relação à atividade física. Revista Brasileira de Nutricão Esportiva, v.3, 2009 .

FLORÊNCIO, I. M.; FLORENTINO, E. R.; SILVA F. L.; MARTINS, R. S.; CAVALCANTI, M.; GOMES, J. Produção de etanol a partir de lactossoro industrial. R. Bras. Eng. Agríc. Ambiental, v. 17, n. 10, p.1088-1092, 2013. 
FLORENTINO, E.; MACEDO, G.; SANTOS, E.; PEREIRA, F; SANTOS, F.; SILVA, E. Caracterização do soro de queijo visando processo de aproveitamento. Revista Higiene Alimentar, v. 19, n. 130, p. 30-32, 2005.

FONTAN, G. C. R. Influência do uso de espessantes na características sensoriais e físico-químicas de bebida láctea com polpa de umbu. 2008. 57f. Dissertação (Mestrado em Engenharia de Alimentos) - Universidade Estadual do Sudoeste da Bahia - UESB, Itapetinga-BA, 2008.

FRIGON, J.; BRETON, J.; BRUNEAU, T.; MOLETTA, R.; GUIOT, S. The treatment of cheese whey wastewater by sequential anaerobic and aerobic steps in a single digester at pilot scala. Bioresource Technology, v. 199, p. 4156-4163, 2009.

GAMBA, J. P.; GARCIA NETO, M.; SILVA, V. M. S. Avaliação de uma fonte simbiótica dietética para avestruzes em crescimento. Facta. Supl., v. 8, p. 33. 2006.

GONTHIER, A. The Effects of Acid Whey on the Environment. Way Over Whey. v. 2, p. 15-49, 2013.

GUGLIELMOTTI, D.; MERCANTI, D.; REINHEIMER, J.; QUIBERONI, A. Review: efficiency of physical and chemical treatments on the inactivation of dairy bacteriophages. Frontiers in microbiology, v. 2, n. 10, 2011.

GUIMARÃES, P. M. R.; TEIXEIRA, J. A.; DOMINGUES, L. Fermentation of lactose to bioethanol by yeasts as part of integrated solutions for the valorization of cheese whey. Biotechnology Advances, v. 28, p. 375-388, 2010.

GUO, X.; TRABLY, E.; LATRILLE, E.; CARRERE, H. Hydrogen production from agricultural waste by dark fermentation: a review. Int J Hydrogen Energy, v. 35, p. 10660-10673, 2010.

HARAGUCHI, F.; ABREU, W.; HEBERT, P. Proteínas do soro do leite: composição, propriedades nutricionais, aplicações no esporte e benefícios para a saúde humana. Revista de Nutrição, v.19, n.4, p.479-488, 2006. 
HAUPTLI, L.; LOVATTO, P.; SILVA, J.; GARCIA, G.; JUNIOR, B. OLIVEIRA J. Níveis de soro de leite integral na dieta de leitões na creche. Ciênc. rural, v. 35, n. 5, p. 1161$1165,2005$.

ILLANES, A. Whey upgrading by enzyme biocatalysis. Electronic journal of biotechnology, v. 14, n. 6, p. 9-9, 2011.

JELEN, P. Whey, Whey Proteins, Lactose and Lactose Derivatives Products: Juice as a Potential Source of Vitamin C. Food Bioprocess Technology, v. 2, p. 368-373, 2009.

KARADAG, D.; KÖROGLU, O.; OZKAYA, B.; CAKMAKCI, M.; HEAVEN, S.; BANKS, C. A review on fermentative hydrogen production from dairy industry wastewater. $\mathbf{J}$ Chem Technol Biotechnol, v. 89, p. 1627-1636, 2014.

KELLY, P. T.; HE, Z. Understanding the application niche of microbial fuel cells in a cheese wastewater treatment process. Bioresource technolog y, v. 157, p. 154-160, 2014.

KEMPKA, A. P.; KRÜGER, R. L.; TREICHEL, H.; VALDUGA, E.; CANSIAN, R.; LUCCIO, M.; OLIVEIRA, D. Formulação de bebida láctea fermentada sabor pêssego utilizando substratos alternativos e cultura probiótica. Ciênc. Tecnol. Aliment. v. 28, p.170$177,2008$.

KIM, D.; THOMA, G.; ULRICH, R.; NUTTER, D.; MILANI, F. Life Cycle Assessment of Cheese Manufacturing in the United States. In: 9th INTERNATIONAL CONFERENCE LCA OF FOOD SAN FRANCISCO, USA. Anais... 8-10 October, 2014.

KOFFI, E.; SHEWFELT, R.; WICKER, L. Storage stability and sensory analysis of uhtprocessed whey-banana beverages. Journal of food quality, v. 28, n. 4, p. 386-401, 2005.

LIMA, A. S. et al. Avaliação físico-química e sensorial de pães de forma enriquecidos com soro de leite em pó. Revista do Instituto Adolfo Lutz, v. 68, n. 3, p. 366-372, 2009. 
LIN, C. S. K. et al. Current and future trends in food waste valorization for the production of chemicals, materials and fuels: a global perspective. Biofuels, Bioprod. Bioref., v. 8, p. 686-715, 2014.

LIRA, H. L. et al. Microfiltração do soro de leite de búfala utilizando membranas cerâmicas como alternativa ao processo de pasteurização. Ciênc. Tecnol. Aliment., v. 29 , n. $1,2009$.

LOLOEI, M.; ALIDADI, H.; NEKONAM, G.; KOR, Y. Study of the coagulation process in wastewater treatment of dairy industries. International. Jornal of Environmental Health Engineering. v. 2, p. 324-342, 2014.

MADERI, T. R. Diagnóstico da gestão integrada em indústrias de laticínios do território de identidade do médio sudoeste. 2014. 63 f. Dissertação (Mestrado em Engenharia de Alimentos). Universidade Estadual do Sudoeste da Bahia. ItapetingaBA, 2014.

MANTOVANI, J. R.; CARRERA, M.; LANDGRAF, P. R. C.; JOSÉ, M.; MIRANDA, J. M. Soro ácido de leite como fonte de nutrientes para o milho. R. Bras. Eng. Agríc. Ambiental, v.19, n.4, p.324-329, 2015.

MARCHI, J.; NESI, A.; BIONDO M.; BORTOLON, E.; REBONATTO, B.; MACHADO, C. Projeto de extensão tecnológica aplicada às agroindústrias familiares rurais integradas ao programa de aquisição de alimentos (PAA) e programa de alimentação escolar (PNAE) localizadas na região sudoeste do Paraná. In: Congresso do Instituto Paranaense de assistência técnica e extensão Rural. Anais... Curitiba: Universidade Tecnológica Federal do Paraná: UTFPR, 2012.

MARQUARDT, L. et al. Indústrias lácteas: alternativas de aproveitamento do soro de leite como forma de gestão ambiental. Tecno-Lógica, v. 15, n. 2, p. 79-83, 2012.

MARTINS, T. D. D. et al. Soro de queijo líquido na alimentação de suínos em crescimento. Revista Ciência Agronômica, v. 39, n. 2, p. 301-307, 2008.

MATOS, A.; ABRAHÃO, S.; MONACO, P. A. V.; SARMENTO, A. P.; MATOS, M. P. Capacidade extratora de plantas em sistemas alagados utilizados no tratamento de 
águas residuárias de laticínios. R. Bras. Eng. Agríc. Ambiental, v.14, n.12, p.13111317, 2010.

MATOS, R. A. Desenvolvimento e mapa de preferência externo de bebida láctea à base de soro e polpa de graviola. 2014. 79f. Dissertação (Mestrado em Engenharia de Alimentos) - Universidade Estadual do Sudoeste da Bahia, ItapetingaBA, 2014.

MENDONÇA, H.; RIBEIRO, C.; BORGES, A.; BASTOS, R. Sistemas Alagados Construídos em Batelada: remoção de Demanda Bioquímica de Oxigênio e regulação de pH no tratamento de efluentes de laticínios. Rev. Ambient. Água, v.10, n.2, 2015.

MIRABELLA, N.; CASTELLANI, V.; SALA, S. Current options for the valorization of food manufacturing waste: a review. Journal of Cleaner Production, v. 65, p. 2841, 2014.

MIZUBUTI, I. Y. Soro de Leite: Composição, processamento e utilização na alimentação. Semina: Ciências Agrárias, v.15, n. 1, p. 80-94, 1994.

MONTEIRO, R. Viabilidade técnica do emprego de sistemas tipo wetlands para tratamento de água cinza visando o reuso não potável. 2009. 71f. Dissertação (Mestrado em Engenharia Civil) - Escola Politécnica da Universidade de São Paulo, São Paulo, 2009.

MOREIRA, R. W. M. et al. Avaliação sensorial e reológica de uma bebida achocolatada elaborada a partir de extrato hidrossolúvel de soja e soro de queijo. Acta Scientiarum. Technology, v. 32, n. 4, p. 435-438, 2010.

NUNES, L. A. Prospecção da valorização e gerenciamento do soro do leite no Litoral Sul da Bahia: um planejamento da cadeia produtiva. 2016. $197 \mathrm{f}$. Dissertação (Mestrado em Desenvolvimento e Meio Ambiente) - Universidade Estadual de Santa Cruz. Ilhéus, 2016.

OLIVEIRA, D.F.; BRAVO, C. E. C.; TONIAL, I. B. Soro de leite: um subproduto valioso. Revista do Instituto de Laticínios Cândido Tostes, v. 67, n. 385, p. 95-115, 2012. 
OLIVEIRA, F. A. Desenvolvimento de bebida láctea não fermentada com soro de leite ácido. 2011. 45 f. Dissertação (Mestrado em Tecnologia em Alimentos) Universidade Tecnológica Federal do Paraná, Francisco Beltrão, 2011.

OLIVEIRA, O. W.; PETROVICK, P. R. Secagem por aspersão (spray drying) de extratos vegetais: bases e aplicações. Rev. bras. Farmacognosia, v. 20, n. 4, p. 12-29, 2010.

PAULA, L. DE; ROLIM, M. M.; BEZERRA NETO, E.; SOARES, T. M.; PEDROSA, E. M. R.; SILVA, E. F. F. Crescimento e nutrição mineral de milho forrageiro em cultivo hidropônico com soro de leite bovino. Revista Brasileira de Engenharia Agrícola e Ambiental, v.15, p.931-939, 2011.

PAVANELI, G. Coagulação, floculação e sedimentação de água com cor ou turbidez elevada. 2001. 76f. Dissertação (Mestrado em Hidráulica e Saneamento) - Escola de Engenharia de São Paulo, São Paulo, 2001.

PELEGRINE, D.; CARRASQUEIRA, R. L. Aproveitamento do soro do leite no enriquecimento nutricional de bebidas. Brazilian Journal of Food Technology, p. 145-151, 2008.

PORTO, L. M.; SANTOS, R. C.; MIRANDA, T. L. S. Determinação das melhores condições operacionais do processo de produção da ricota. Bol. Centro Pesqui. Process. Aliment, v. 23, n. 1, p. 173-182, 2005.

PRAZERES, A. R.; CARVALHO, F.; RIVAS, J. Cheese whey management: A review. Journal of Environmental Management, v. 110, p. 48-68, 2012.

RAD, S. J.; LEWIS, M. J. Water utilisation, energy utilisation and waste water management in the dairy industry: A review. International Journal of Dairy Technology, v. 67, n. 1, 2014.

RIBEIRO, D.; LACERDA, A. Oportunidades e desafios da cadeia produtiva. Revista Indústria de Laticínios, Balanço e perspectiva de lácteos, v.1, n.2, p. 24-25. 2012.

RIBEIRO, O. A. S. Bebida láctea fermentada elaborada com camellia sinensis. 
Diamantina. 2013. 59f. Dissertação (Mestrado em Ciência e Tecnologia de Alimentos) - Universidade Federal dos Vales do Jequitinhonha e Mucuri - UFVJM, 2013.

RIVAS, J. et al. Treatment of cheese whey wastewater: combined coagulationflocculation and aerobic biodegradation. Journal of agricultural and food chemistry, v. 58, n. 13, p. 7871-7877, 2010.

SANTOS, C.T. et al. Influência da concentração de soro na aceitação sensorial de bebida láctea fermentada com polpa de manga. Alimentos e Nutrição, v. 19, n. 1, p.55-60, 2008.

SARKAR, B.; CHAKRABARTI, P. P.; VIJAYKUMAR, A.; KALE, V. Wastewater Treatment in dairy industries - possibility of reuse. Journal Desalination, v. 195, p. 141-152, 2006.

SILVA, A. N. Modelagem, simulação e análise técnico-financeira de uma unidade de processamento de soro de leite para produção integrada de concentrado proteico, lactose e etanol. 2011. 97f. Dissertação (Mestrado em Ciência e Tecnologia de Alimentos) - Universidade Federal de Viçosa - UFV, Viçosa, 2011.

SILVA, K.; BOLINI, H. Avaliação sensorial de sorvete formulado com produto de soro ácido de leite bovino. Ciênc. Tecnol. Aliment, v. 26, p. 116-122, 2006.

SILVA, L. F. M.; FERREIRA, K. S. Avaliação de rotulagem nutricional, composição química e valor energético de queijo minas frescal, queijo minas frescal "light" e ricota. Alimentos e Nutrição Araraquara, v. 21, n. 3, p. 437-442, 2010.

SOUZA, J. F.; JERÔNIMO, C. E. M. Valorização e Aproveitamento de Subprodutos Lácticos: Extração de Proteínas e Hidrogenação Catalítica da Lactose. Revista Técnológica Santa Cruz do Sul, v. 16, n. 1, p. 11-18, 2012.

TEIXEIRA, L.; FONSECA, L. Perfil físico-químico do soro de queijos mozarela e minaspadrão produzidos em várias regiões do estado de Minas Gerais. Arq. Bras. Med. Vet. Zootec, v. 60, n. 1, p. 243-250, 2008. 
TONI, J. C. V.; IMAMURA, K. B.; DORTA, C. Reaproveitamento do soro de leite bovino para produção de biomassa por Kluyveromyces Marxianus. Revista Alimentus, v. 2, p. 36-57, 2012.

VALDUGA, E.; PAVIANI, L. C.; MAZUR, S. P.; FINZER, J. R. D. Aplicação do soro de leite em pó na panificação. Alim. Nutr. Araraquara, v.17, n.4, p.393-400, 2006.

VENTURINI FILHO, W.G. Bebidas não alcoólicas. Rev. Ciência e Tecnologia, v. 2, p. $423-447,2010$.

WISSMANN, M. A.; HEIN, A. F.; NEULS, H. Geração de resíduos: uma análise de ecoeficiência nas linhas de produção em uma indústria de laticínio e a influência sobre os custos ambientais. Custos e @gronegócio on line, v. 9, n. 4, 2013.

YETIM, H.; MÜLLER, W. D.; DOGAN, M.; KLETTNER, P. G. Using fluid whey in comminuted meat products: effects on textural properties of frankfurtertype sausages. Journal of Muscle Foods, v. 17, n. 3, p. 354-366, 2006.

Recebido em: 2016-08-18 Aceito em: 2016-11-23 